\title{
CONDITION BASED MONITORING OF ROTATING MACHINES USING PIEZOELECTRIC MATERIAL
}

\author{
Nirmal Kumar Kushwaha ${ }^{1}$, Babaria Rinkesh ${ }^{2}$, Patel Prince ${ }^{3}$, Mehta Hardik ${ }^{4}$ \\ ${ }^{1}$ Assistant professor, Department of Mechanical Engineering, Babaria Institute of Technology, Gujarat, India \\ ${ }^{2}$ Department of Mechanical Engineering, Babaria Institute of Technology, Gujarat, India \\ ${ }^{3}$ Department of Mechanical Engineering, Babaria Institute of Technology, Gujarat, India \\ ${ }^{4}$ Department of Mechanical Engineering, Babaria Institute of Technology, Gujarat, India
}

\begin{abstract}
Now days, vibration is drawing much more concern in almost all industry. Vibration possesses existence in every machine. Due to this vibration the efficiency of operation decreases further it creates very much noisy environment. It causes wearing and tearing of material in components, so it is necessary to prevent vibration in the system. The use of piezoelectric materials to capitalize on the ambient vibrations surrounding a system is one method that has seen a dramatic rise in use for condition monitoring. Piezoelectric materials have a crystalline structure that provides them with the ability to transform mechanical strain energy into voltage charge. Our efforts are for utilizing this effect in Lathe machine for monitoring condition of machine. And also monitor the condition of the machine to increase the quality of the product hence we can compete in the today's competitive market.
\end{abstract}

Keywords: Condition monitoring, CBM, Piezo based monitoring, CBM of lathe machine.

\section{INTRODUCTION}

Condition monitoring of machinery is the measurement of various parameters related to the mechanical condition of the machinery (such as vibration, bearing temperature, oil pressure, oil debris, and performance), which makes it possible to determine whether the machinery is in good or bad mechanical condition.

If the mechanical condition is bad, then condition monitoring makes it possible to determine the cause of the problem. Once the integrity of a machine has been estimated, this information can be used for many different purposes. Different types of data that can be useful for assessing machine condition and these should not be ignored.

\subsection{Condition Monitoring-Concept}

$\mathrm{CBM}$ is determining the condition of equipment, machines and systems etc. by observing, checking, measuring, and monitoring signals which was obtained.

Using piezoelectric materials connected with transducer can measure voltage and by help of harmonic oscillator measure frequency of vibration. Also we can find linearity and measuring precision and Accuracy. In condition monitoring we take a different parameter reading like frequency, voltage, force and compare that parameter in different condition, forces of machines and analyze.

Condition monitoring (or, colloquially, CM) is the process of monitoring a parameter of condition in machinery (vibration, temperature etc.), in order to identify a significant change which is indicative of a developing fault.

\subsection{Predictive Maintenance}

The use of conditional monitoring allows maintenance to be scheduled, or other actions to be taken to prevent failure and avoid its consequences. Condition monitoring has a unique benefit in that conditions that would shorten normal lifespan can be addressed before they develop into a major failure. Condition monitoring techniques are normally used on rotating equipment and other machinery (pumps, electric motors, internal combustion engines, presses), while periodic inspection using non-destructive testing techniques and fit for service (FFS).

\section{AREA OF WORK}

We are attempting to (1) Measure the vibrations on one of the lathe by providing a cheap and alternative method to conventional vibrometers. (2) Attempt to establish a condition based monitoring for any typical rotating machine using Piezo-electric crystals.

Vibrations produced by the machine do not transmit into floor properly, but they reflect high forces back onto machine \& this reflected forces has been converted into heat. 


\subsection{Need of Vibration Analysis}

Vibration Analysis is necessary for providing information as below:

1. Evaluation of machine condition

2. Recognition of on-going machine damage symptoms.

3. Identification of the cause and the damaged components

4. Prognosis of remaining service life.

\section{PROPOSED METHOD OF WORK}

As described above many methods can be used for vibration analysis. From that we select using piezoelectric materials to absorb the vibration and from that signal produce in the form of voltage.

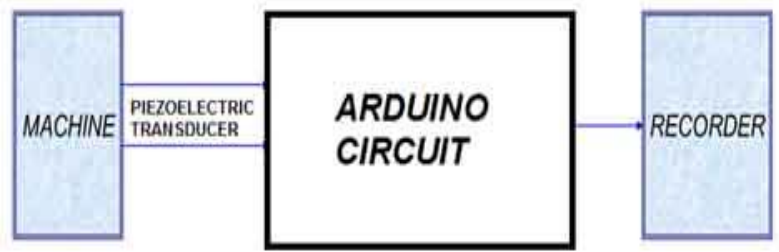

Fig-1: Vibration measuring and analysis system

\subsection{Why we use this method?}

The direct measurement is required without any great deal of post processing (analysis or calculation.)

1. Equipment is cheaper (approx... 100 times) than any professional vibrometer. Hence permanent installation to monitor is possible.

2. Variation in accuracy and precision by choosing different type of software.

3. Data can be directly logged into computer and plotted if necessary.

\section{IMPLEMENTATION}

\subsection{Piezoelectric Material}

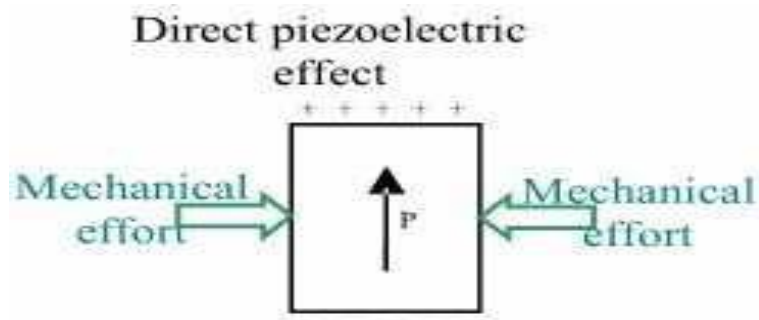

\section{Charge Apparition}

Fig-2: Electromechanical conversion via piezoelectricity

These devices contain one or more piezoelectric crystal elements (natural quartz or man-made ceramics), which produce voltage when stressed in tension, compression or shear. This is the piezoelectric effect. The voltage generated across the crystal pole faces is proportional to the applied force.

\section{(Physical Quantity) $\longrightarrow$ (Electrical Quantity)}

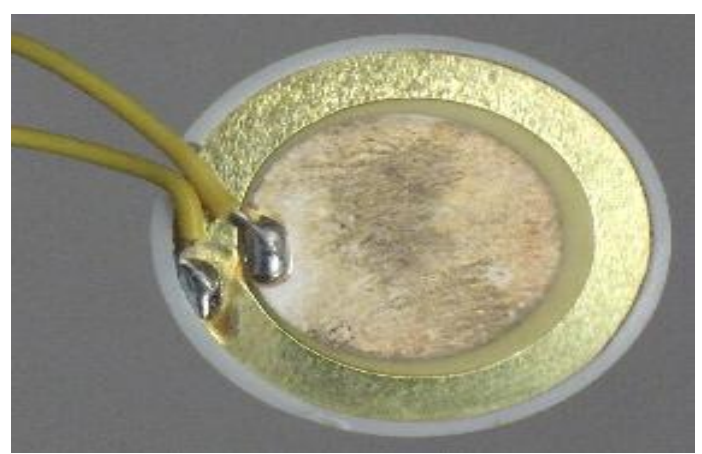

Fig-3: Piezoelectric material

\subsection{Electronic Circuit}

This sketch reads a piezo element to detect a vibration. This circuit is receiving all Analog signals from the piezo-electric transducer and transfer to the computer through cable in digital form. In simple it converts Analog quantity into digital quantity.

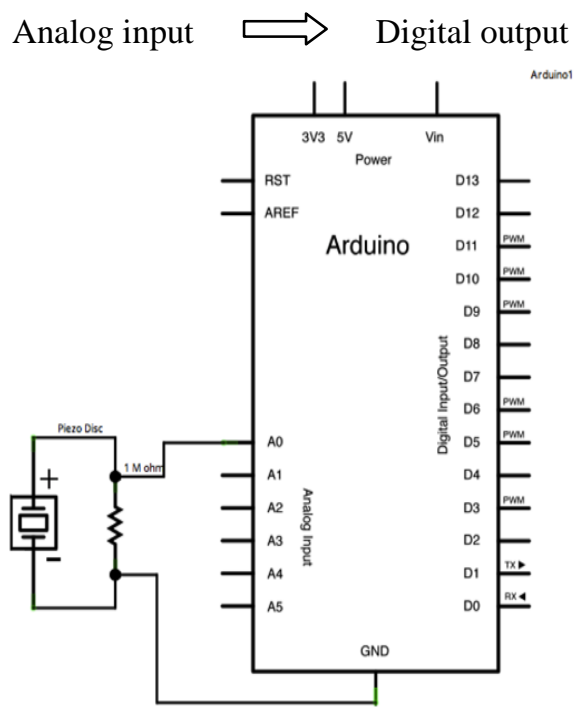

Fig-4: Electronic circuit

\subsection{Use of Tuning Fork in Project}

Tuning fork is used only for testing purpose in the condition monitoring i.e. we can measure frequency of machine which is to be monitored. By measuring the frequency we can plot various linearity and precision graph accuracy graph for various conditions.

\subsection{Electrical Resistor}

Resistor is a devise to control voltage of the system. Its protect the system for heavy current. In this systemwe used $1 \mathrm{ohm}$ capacity of resistor.

\section{WORKING}

The whole system is divided into a several sub-system which is not only convert, measure or transfer the different quantity of the system to the other. 


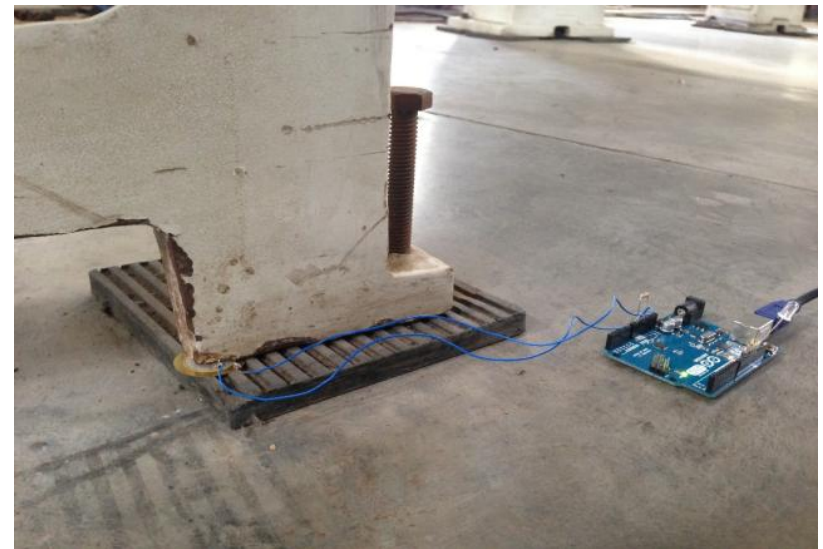

Fig-5: Working module

This system attaching piezo-electric material is placed between the lathe machine based and the foundation based to absorb the vibration of the machine which produces during the working condition. And this Piezo-electric material is solder at two points in centre of the material which work as a positive and the outer face of the material work as a negative.

The piezo materials positive wire is connected to the analog pin 0 and negative wire is connected to the ground. With this resister of $1 \mathrm{ohm}$ one end is connected in analog pin 0 and the other end is connected to the other ground of the circuit. Same as end of the circuit the cable is connected to the computer for signal transfer. This signal is in the form of digital quantity. Now the whole system is assembled. Second step is to check that the system is working or not for this knock operation is used. We used the software to note a digital signal in the form of reading.

\subsection{Knock}

This sketch reads a piezo element to detect a knocking sound. A knock on a door, table, or other solid surface is the example of knocking.

A piezo is an electronic device that generates a voltage when it's physically deformed by a vibration, sound wave, or mechanical strain. Similarly, when you put a voltage across a piezo, it vibrates and creates a tone. Piezo can be used both to play tones and to detect tones.

The sketch reads the piezo output using the analog Read command, encoding the voltage range from 0 to 5 volts to in a process referred to as analog-to-digital conversion. If the sensors output is stronger than a certain threshold, your Arduino will send the string "Knock!" to the computer over the serial port. To get higher threshold we hit the material by means of finger. If we hit the material in low intensity knock is not noted in the screen.

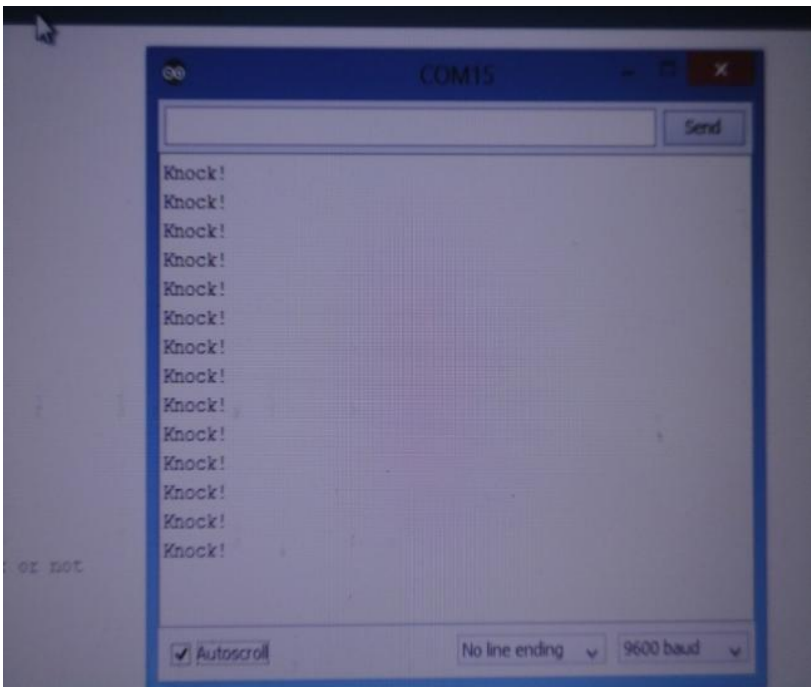

Fig-6: Knock Analysis

By knocking we get that voltages is generated from the vibration but it is not given the value of it, some change is require to get the value of voltage in frequent manner so we can generate value of voltage and thus from that value we get the frequency of vibration. So we change the programme on Arduino circuit which shows Analog voltage reading in serial monitor.

\subsection{Read Analog Voltage}

Read analog voltage is a process of convert the digital form of energy into a voltage form. As we tested that circuit is working then moving further circuit connection is same as the knock process only the difference is to change program of read analog voltage.

Then after put the piezo-electric material under the lathe machine which is going to conduct before machine has been started. Check the whole system is working or not by means of see that the reading has come zero continuously or not. If there reading are not come then check that all connection is ok then check further.

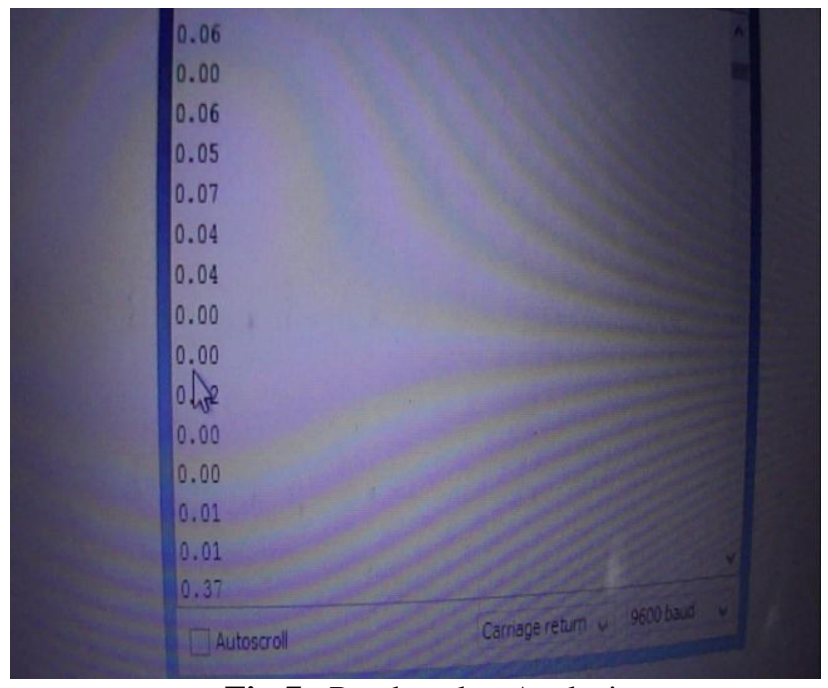

Fig-7: Read analog Analysis 
When machine has been started the serial monitor show reading in positive value that value is in voltage form we take this reading value for plotting graph.

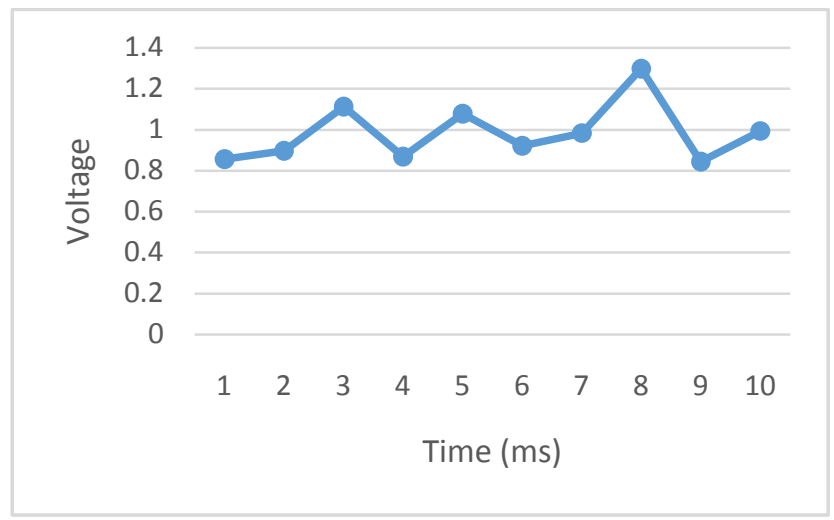

Fig-8: Piezo structure Frequency variation

Fig shows various frequencies in different layer of piezoelectric material, if some range of frequency is obtained in piezo structure but it is not uniform at all time. But when the structure of the material changes it goes up to the upper layer of frequency. So we take the maximum of the voltages obtained by the piezoelectric material.

\section{RESULT ANALYSIS}

\subsection{Step - 1}

From the tuning fork we get the voltages related to the standard frequency, from this reading various graphs are plotted between frequency vs voltages which is obtained from the standard tuning fork, various readings are

Table 1: Voltages related to the standard frequency

\begin{tabular}{|c|c|c|c|c|c|c|c|c|c|}
\hline & & 10hz & $15 \mathrm{hz}$ & $20 \mathrm{hz}$ & $25 \mathrm{hz}$ & 30hz & $35 \mathrm{hz}$ & $40 \mathrm{hz}$ & \\
\hline 1 & 0 & 0 & 0 & 0 & 0 & 0 & 0 & 0 & 0 \\
\hline 2 & 1.7 & 2.65 & 2.03 & 0.38 & 3.31 & 3.31 & 1.09 & 1.18 & 2.56 \\
\hline 3 & 0.1 & 0 & 0 & 1.02 & 0 & 0 & 2.49 & 3.27 & 1.5 \\
\hline 4 & 0 & 0.91 & 2.04 & 3.3 & 0 & 0 & 3 & 1.48 & 0 \\
\hline 5 & 2.42 & 0.06 & 0 & 0 & 2.15 & 2.15 & 1.63 & 0.9 & 0 \\
\hline 6 & 0 & 0 & 2.05 & 1.65 & 0 & 0 & 0.18 & 0 & 0.02 \\
\hline 7 & 0.11 & 1.8 & 0 & 0 & 1.2 & 1.2 & 0 & 0 & 2.81 \\
\hline 8 & 1.68 & 0 & 2.05 & 0 & 0.71 & 0.71 & 0 & 0 & 1.25 \\
\hline 9 & 0 & 2.7 & 0 & 1.01 & 0 & 0 & 1.33 & 2.03 & 0 \\
\hline 10 & 1.91 & 0 & 2.06 & 0 & 2.62 & 2.62 & 2.23 & 0 & 4.8 \\
\hline 11 & 0 & 1.67 & 0 & 2.69 & 0 & 0 & 0 & 0 & 0 \\
\hline 12 & 0 & 0 & 2.07 & 0 & 0 & 0 & 0 & 0.3 & 1.42 \\
\hline 13 & 2.23 & 0 & 0 & 2.55 & 2.86 & 2.86 & 1.25 & 2.11 & 0 \\
\hline 14 & 0 & 1.06 & 2.07 & 0 & 0 & 0 & 2.28 & 3.02 & 1.19 \\
\hline 15 & 0.31 & 0 & 0 & 0.86 & 0.47 & 0.47 & 0 & 1.22 & 0 \\
\hline 16 & 1.48 & 2.77 & 2.08 & 0.09 & 1.44 & 1.44 & 0 & 0 & 1.01 \\
\hline 17 & 0 & 0 & 0 & 0 & 0 & 0 & 1.17 & 0 & 0 \\
\hline 18 & 2.11 & 2.41 & 2.08 & 1.79 & 1.91 & 1.91 & 2.38 & 0 & 0.73 \\
\hline 19 & 0 & 0 & 0 & 0 & 0 & 0 & 0 & 2.9 & 0 \\
\hline 20 & 0 & 0.68 & 2.09 & 3.27 & 0 & 0 & 0 & 1.13 & 0.49 \\
\hline 21 & 2.68 & 0.3 & 0 & 0 & 3.31 & 3.67 & 1.09 & 2.93 & 0 \\
\hline 22 & 0 & 0 & 2.09 & 1.77 & 0 & 0 & 2.44 & 2.2 & 0.26 \\
\hline 23 & 0.52 & 2.04 & 0 & 0 & 0 & 0 & 0 & 0.38 & 0 \\
\hline 24 & 1.27 & 0 & 2.1 & 0.07 & 2.17 & 2.17 & 0 & 0 & 0.02 \\
\hline 25 & 0 & 2.14 & 0 & 0.88 & 0 & 0 & 1.03 & 4.26 & 0.2 \\
\hline 26 & 2.32 & 0 & 2.1 & 0 & 1.19 & 1.19 & 2.53 & 0 & 0 \\
\hline 27 & 0 & 1.43 & 0 & 2.57 & 0.72 & 0.72 & 0 & 0.15 & 0.43 \\
\hline 28 & 0 & 0 & 2.11 & 0 & 0 & 0 & 0 & 1.96 & 0 \\
\hline 29 & 2.83 & 0 & 0 & 2.65 & 2.61 & 2.61 & 0.95 & 3.15 & 0.66 \\
\hline 30 & 0 & 1.3 & 2.12 & 0 & 0 & 0 & 2.6 & 1.37 & 0 \\
\hline 31 & 0.73 & 0 & 0 & 0.98 & 0 & 0 & 0 & 0 & 0.89 \\
\hline 32 & 1.07 & 2.8 & 2.12 & 0 & 2.87 & 2.87 & 0 & 3.7 & 0 \\
\hline 33 & 0 & 0 & 0 & 0 & 0 & 0 & 0.86 & 0 & 1.13 \\
\hline 34 & 2.52 & 2.17 & 2.13 & 1.67 & 0.45 & 0.45 & 2.67 & 0 & 0 \\
\hline 35 & 0 & 0 & 0 & 0 & 1.46 & 1.46 & 3.89 & 0.98 & 1.36 \\
\hline
\end{tabular}

From all this reading we plot the calibration curve from the vibration analysis which is shown below.

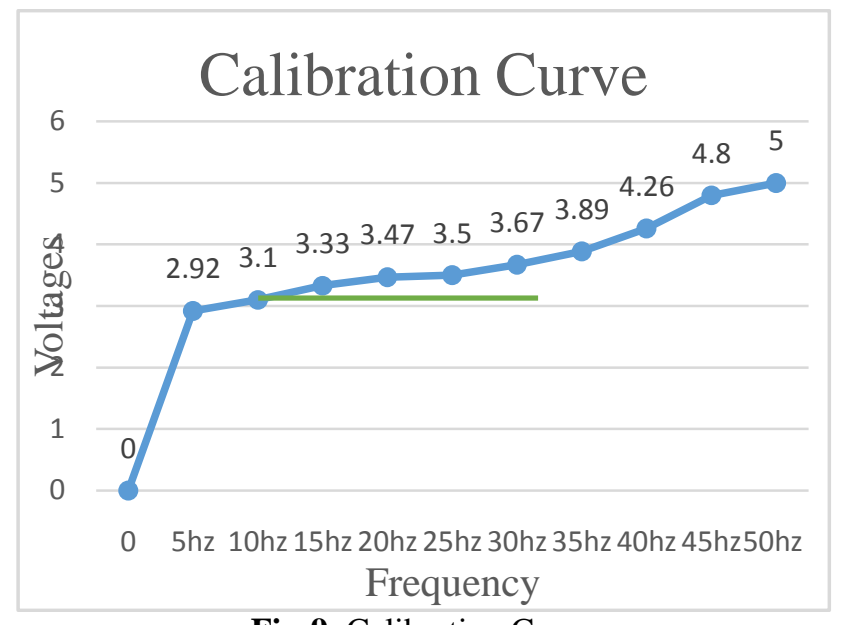

Fig-9: Calibration Curve

Slope of this calibration curve gives the multiplication factor which gives the relation between the two axes, so we can get the frequencies from the different obtained voltages

\subsection{Step - 2}

We performed the experiment with this system on the lathe machine because there are most of the operations are performed on the lathe in the company. Lathe machine include many operations but we focus on maximum performed operations (turning, grooving, knurling etc.).

Reading of voltages obtained during these operations is.

Table 2: Voltages obtained during these operations

\begin{tabular}{|c|c|c|c|}
\hline Time & Grooving & Turning & Knurling \\
\hline 1 & 0 & 0 & 0 \\
\hline 2 & 0.15 & 0.01 & 0.01 \\
\hline 3 & 0.13 & O & O \\
\hline 4 & 0.19 & 0.6 & $\mathbf{O}$ \\
\hline 5 & O & 0.03 & 0.13 \\
\hline 6 & 0.07 & 0.13 & O \\
\hline 7 & 0.21 & 0.07 & 0.25 \\
\hline 8 & 0.09 & O & 0.01 \\
\hline 9 & 0.12 & 0.26 & 0.08 \\
\hline 10 & 0.22 & 0.1 & O \\
\hline 11 & O & 0.19 & O \\
\hline 12 & 0.06 & O & O \\
\hline 13 & 0.09 & 0.15 & 0.1 \\
\hline 14 & O & O & O \\
\hline 15 & 0.2 & 0.07 & 0.03 \\
\hline 16 & 0.11 & 0.12 & O \\
\hline 17 & 0.12 & 0.17 & 0.06 \\
\hline 18 & O & O & O \\
\hline 19 & 0.07 & 0.13 & 0.08 \\
\hline 20 & 0.24 & O & 0.02 \\
\hline 21 & O & 0.25 & 0.01 \\
\hline 22 & 0.19 & O & 0.07 \\
\hline 23 & 0.06 & 0.05 & O \\
\hline 24 & O & O & $\mathrm{O}$ \\
\hline 25 & 0.21 & 0.1 & $\mathrm{O}$ \\
\hline 26 & 0.12 & O & O \\
\hline 27 & O & 0.22 & O \\
\hline 28 & 0.11 & O & O \\
\hline 29 & 0.02 & 0.45 & 0.12 \\
\hline 30 & O & O & O \\
\hline 31 & 0.1 & 0.12 & $\mathrm{O}$ \\
\hline 32 & O & O & 0.11 \\
\hline 33 & O & 0.13 & O \\
\hline 34 & O & O & 0.17 \\
\hline
\end{tabular}


Analyse the condition of various operations here

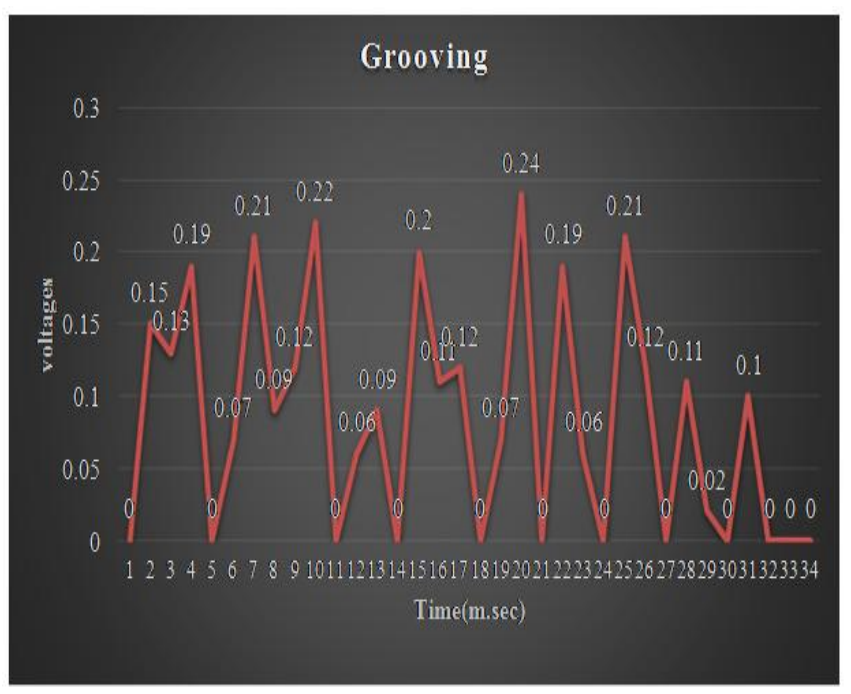

Fig-9: Grooving Analysis

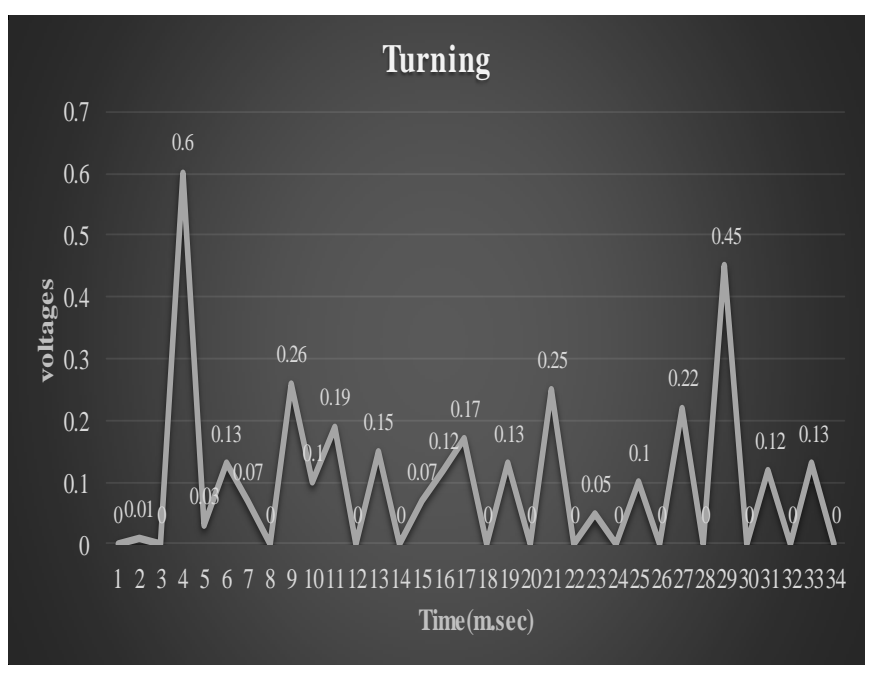

Fig-10: Turning Analysis

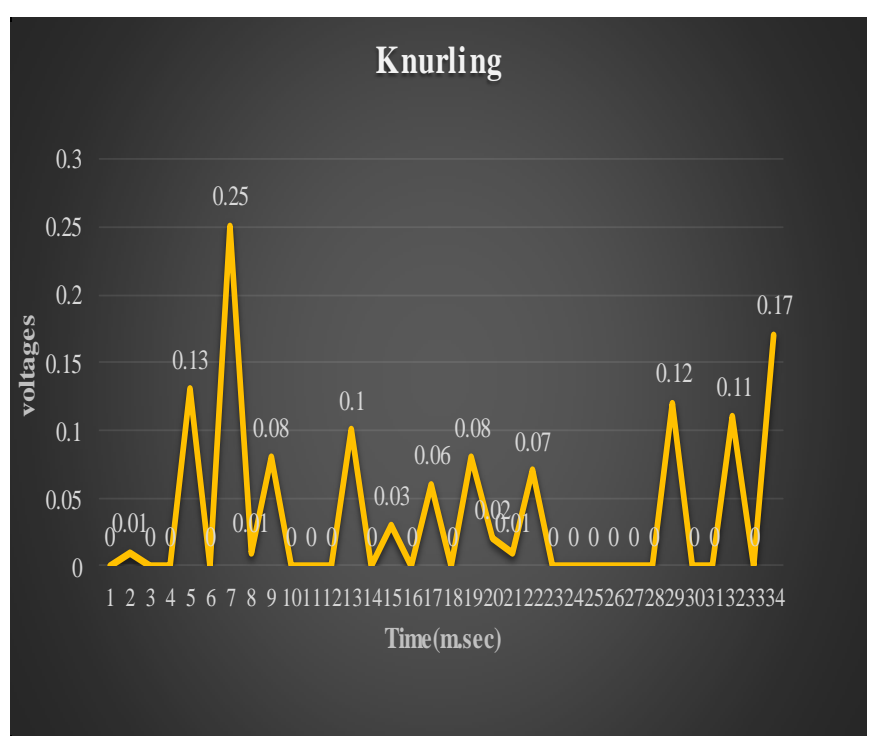

Fig-11: Knurling Analysis

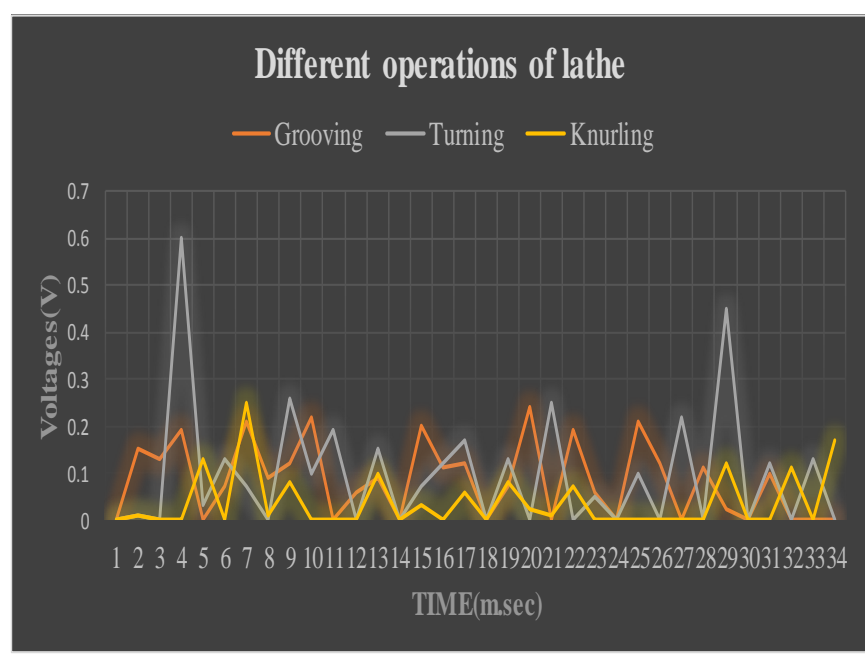

Fig-12: Analysis of Different operations of lathe

As we show that for different operation the voltage generated is different at any time interval. It is clear that for different operation some internal parameter of the operation is responsible for it.

For different operations, value of frequency also differs that's why we observed there are some parameter which affect during the operation so we short out the possible factor that affect the process is noted below.

Table 3: Lathe operation Analysis

\begin{tabular}{|l|l|l|l|}
\hline OPERATIONS & Turning & Grooving & Knurling \\
\cline { 1 - 2 } PARAMETER & & No & Yes \\
\hline $\begin{array}{l}\text { High Cutting } \\
\text { speed }\end{array}$ & Yes & Yes & No \\
\hline $\begin{array}{l}\text { Loose } \\
\text { foundation }\end{array}$ & More & $\begin{array}{l}\text { Less than } \\
\text { turning }\end{array}$ & $\begin{array}{l}\text { More than } \\
\text { grooving }\end{array}$ \\
\hline Misalignment & No & No & Yes \\
\hline Human error & Yes & Yes & Yes \\
\hline
\end{tabular}


So, if we found the vibration frequency more which has been shown in the above graph than we decide the problem and check out them to reduce the vibration for increasing the quality of product. Above table describe the parameter which affects most for the particular operation.

\section{CONCLUSIONS}

We studied that for different operations, the frequency value is change due to the effect of particular parameter if we control those parameter in such a way that the operation performance is carried out smoothly than the vibration frequency is less affected and it will not harm to the machine as well as component or a product. Also this system gets the exact frequency at any time interval during the operation.

By this we can observed and get the exact parameter which is responsible for high vibration. Once we get the particular parameter by which vibration is developed then we can control those parameter and monitoring the machine by means of adjusting according condition based monitoring by using piezoelectric material. This can use in future for a maintenance purpose; also it can protect the machine from breakdown.

\section{REFERENCES}

[1]. Chris K. Mechefske "Machine Condition Monitoring and Fault Diagnostics" Queen's University.

[2]. Mitchell, J.S. 1981. "An Introduction to Machinery Analysis and Monitoring", Penwell, Los Angeles.

[3]. Reeves, C.W. 1999. "The Vibration Monitoring Handbook", Coxmoor, Oxford.

[4]. Glynne-Jones P, Beeby SP and White NM 2001 Towards "a piezoelectric vibration powered microgenerator" IEE Proceedings - Science, Measurement and Technology. 148(2) 68-72.

[5]. Michele Lucente, "Condition Monitoring System in Wind Turbine Gearbox", Master Thesis, KTH, Royal Institute of Technology, School of Electrical Engineering, Sweden, April 2008.

[6]. Tavner, P.J, "Review of condition monitoring of rotating electrical machines", Sch. of Eng., Durham Univ., Durham, Publised in Electric Power Applications, IET, Volume: 2 Issue: 4, ISSN: 1751-8660, pp. 215 - 247, July 2008.

[7]. Kazuhiko Adachi and Tohru Tanaka "A Preliminary Study of Piezoelectric Vibration Energy Harvester for Vibration Condition Monitoring Applications of Rotating Machinery" ASME 2008 Conference on Smart Materials, Adaptive Structures and Intelligent Systems, Paper No. $\begin{array}{llll}\text { SMASIS2008-483, } & \text { pp. } & 739-747 ; & 9\end{array}$ pages doi:10.1115/SMASIS2008-483.

[8]. Lyon, R.H. 1987. "Machinery Noise and Diagnostics", Butterworth, Boston.

[9]. K. Adachi "Piezoelectric vibration energy harvesting using Casing vibration of industrial rotating machinery Due to its mass imbalance" Department of Mechanical Engineering, Kobe University, Kobe, Japan.
[10]. J Michael Robichaud, "Reference Standards for Vibration Monitoring and Analysis", Bretech Engineering Ltd., 70 Crown Street, Saint John, NB Canada, 2004.

[11]. Asif Saeed "Online Condition Monitoring System for Wind Turbine" Blekinge Institute of Technology October 2008.

[11]. Hari Prasad Konka "characterization of composite piezoelectric Materials for smart joint applications" Louisiana State University and Agricultural and Mechanical College August, 2010.

\section{BIOGRAPHIES}

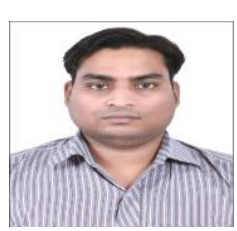

Mr. Nirmal Kumar Kushwaha received the graduate degree in Industrial and Production Engineering from Uttar Pradesh Technical University in 2010, M.Tech. in Mechanical Engineering from Sardar Vallabhbhai National Institute of Technology, Surat in 2012. His research interest includes analysis of vibrations in machines, Kinematics and Dynamics of Machines and mechanism, Tribology, and Robotics. He is a Member of Indian Society for Technical Education. He also serves as member of Editorial Board for International Journal of Emerging Technology and Advanced Engineering, INDIA. Presently he is working as an Assistant Professor in Mechanical Engineering Department at Babaria Institute of Technology, Vadodara, Gujarat.

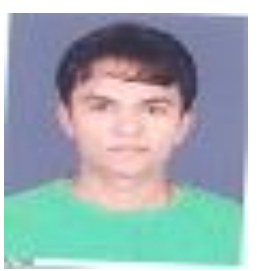

Mr. Babaria Rinkesh received the graduate degree in Mechanical Engg. From Babaria Institute of Technology, Vadodara, Gujarat, India. His area of research includes vibration analysis.

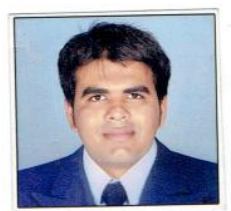

Mr. Patel Prince received the graduate degree in Mechanical Engg. From Babaria Institute of Technology, Vadodara, Gujarat, India. His area of research includes vibration analysis.

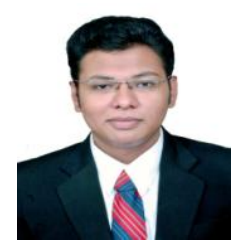

Mr. Mehta Hardik received the graduate degree in Mechanical Engg. From Babaria Institute of Technology, Vadodara, Gujarat, India. His area of research includes vibration analysis. 